\title{
Rupture and Migration of an Endovascular Stent in the Brachiocephalic Trunk Causing a Vertebral Steal Syndrome
}

\author{
D. Periard · E. Haesler $\cdot$ D. Hayoz • \\ L. K. Von Segesser · S. D. Qanadli
}

Received: 31 July 2007/ Accepted: 16 November 2007/Published online: 3 January 2008

(C) Springer Science+Business Media, LLC 2007

\begin{abstract}
Delayed stent fracture has been observed in many different arteries and may represent a risk factor for restenosis. We describe the case of a delayed rupture of an endovascular brachiocephalic trunk stent. The complete fracture allowed a fragment to migrate distally and tilt, resulting in a hemodynamic pattern similar to that of a prevertebral stenosis with complete inversion of the homolateral vertebral blood flow. The induced vertebral steal syndrome as well as the risk of cerebral embolism was corrected by an aortobrachiocephalic bypass and resection of the ruptured stent.
\end{abstract}

Keywords Arteriopathy · Stent rupture ·

Vertebral steal syndrome

\section{Introduction}

Endovascular stent implantation is a major tool in the management of peripheral arterial disease [1-3]. Supra-

D. Periard · E. Haesler · D. Hayoz

Service of Angiology, University Hospital (CHUV), Lausanne, Switzerland

\section{K. Von Segesser}

Cardiovascular and Metabolic Diseases Center, University

Hospital (CHUV), Lausanne, Switzerland

S. D. Qanadli

Department of Radiology, University Hospital (CHUV),

Lausanne, Switzerland

D. Periard $(\bowtie)$

Department of Angiology, PMU 07, Bugnon 44, University

Hospital (CHUV), 1011 Lausanne, Switzerland

e-mail: Daniel.Periard@chuv.ch aortic artery angioplasty and stenting have been performed for many years with a satisfying outcome [4-6]. Delayed stent rupture has been observed in arteries with high mechanical stress and is considered a risk factor for in-stent restenosis [7]. We present a case of delayed fracture of a brachiocephalic stent with migration of the distal fragment causing a vertebral steal syndrome.

\section{Case Report}

A 62-year-old man was referred to us for intermittent dizziness and right arm claudication. His cardiovascular risk factors were type 2 diabetes and past smoking. Clinical examination revealed an asymmetry of brachial blood pressure, with the right-arm systolic pressure $30 \mathrm{~mm} \mathrm{Hg}$ below that of the left arm. A stenosis of the right brachiocephalic trunk was diagnosed by echo Doppler, with monophasic blood flow in the right subclavian artery. Selective angiography by femoral approach confirmed an $80 \%$ stenosis of the brachiocephalic trunk (Fig. 1). Direct stenting was performed with a balloon-expandable silicone carbide-coated stent (Peiron; Biotronik, Berlin) $8 \mathrm{~mm}$ in diameter and $26 \mathrm{~mm}$ long. The stent was deployed at 6 atm during $20 \mathrm{~s}$. The angiogram at the end of the procedure disclosed no significant residual stenosis and correct position of the stent, with a small defect in the wall apposition of the cranial segment, due to a poststenotic dilatation of the artery (Fig. 2). The stent was not further balloonexpanded. Brachial blood pressure difference disappeared after angioplasty. A Doppler examination disclosed restored triphasic arterial flow in the right arm after the procedure.

Two years later, the patient presented a relapse of blood pressure asymmetry. Doppler analysis showed antegrade 


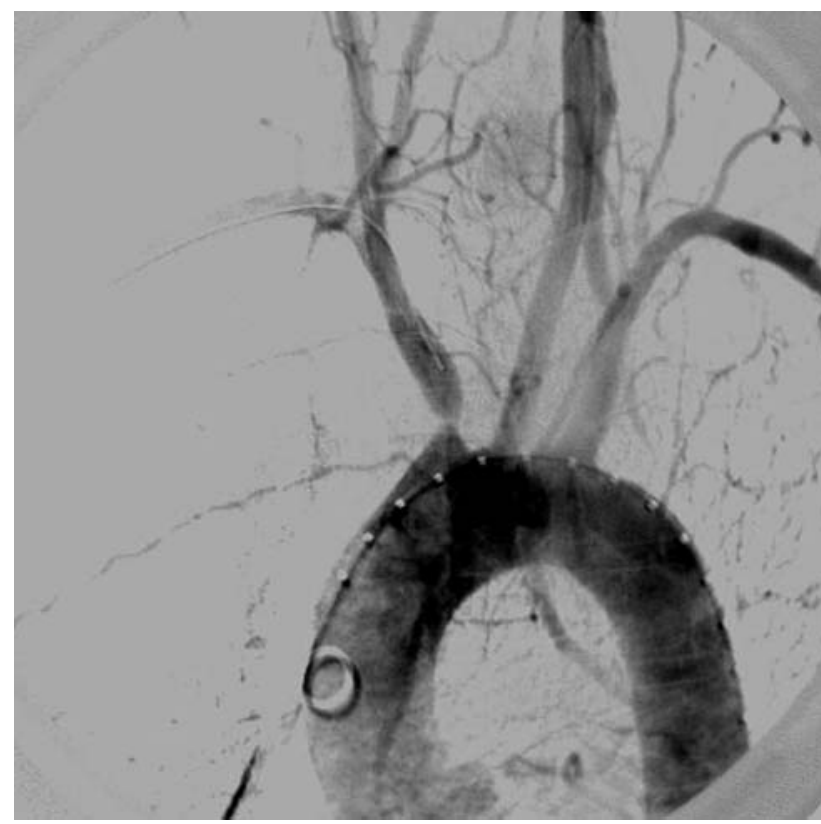

Fig. 1 Selective angiography showing an $80 \%$ stenosis of the right brachiocephalic trunk

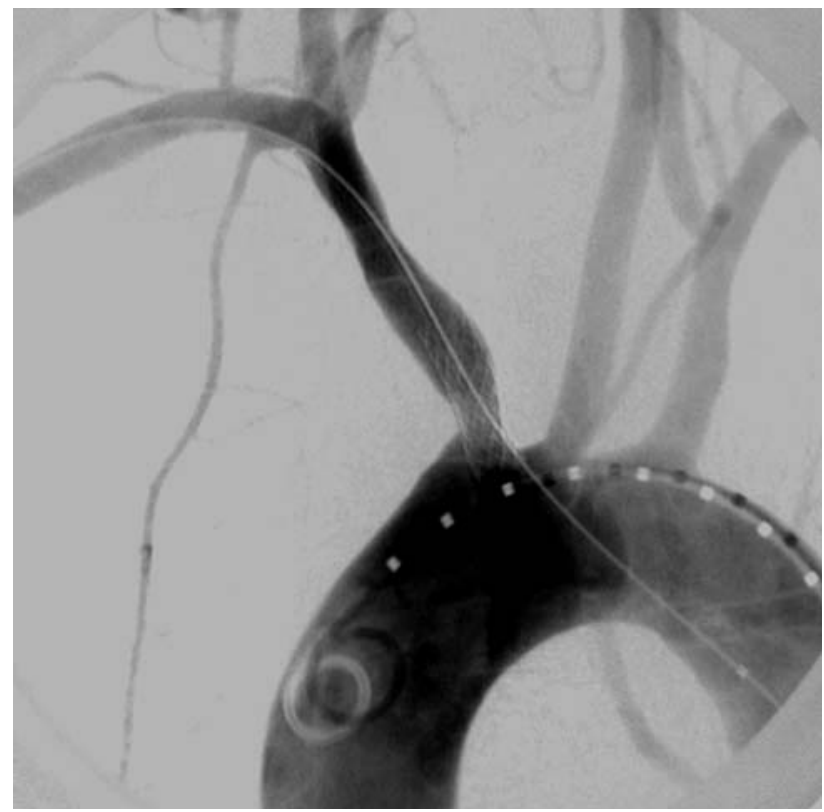

Fig. 2 Angioplasty and stenting of the stenosis resulting in satisfactory lumen restoration. Note the lack of perfect apposition of the cranial stent extremity on the wall, due to a poststenotic arterial dilatation

monophasic arterial flow of the right subclavian and right common carotid artery. Right vertebral flow was totally inverted. We postulated an in-stent restenosis. High-resolution (slice thickness of $0.625 \mathrm{~mm}$ ) multidetector CT angiography (Lightspeed VCT; GE Medical Systems, Milwaukee, WI, USA) showed a rupture of the stent, with migration of its cranial fragment (Fig. 3). Selective

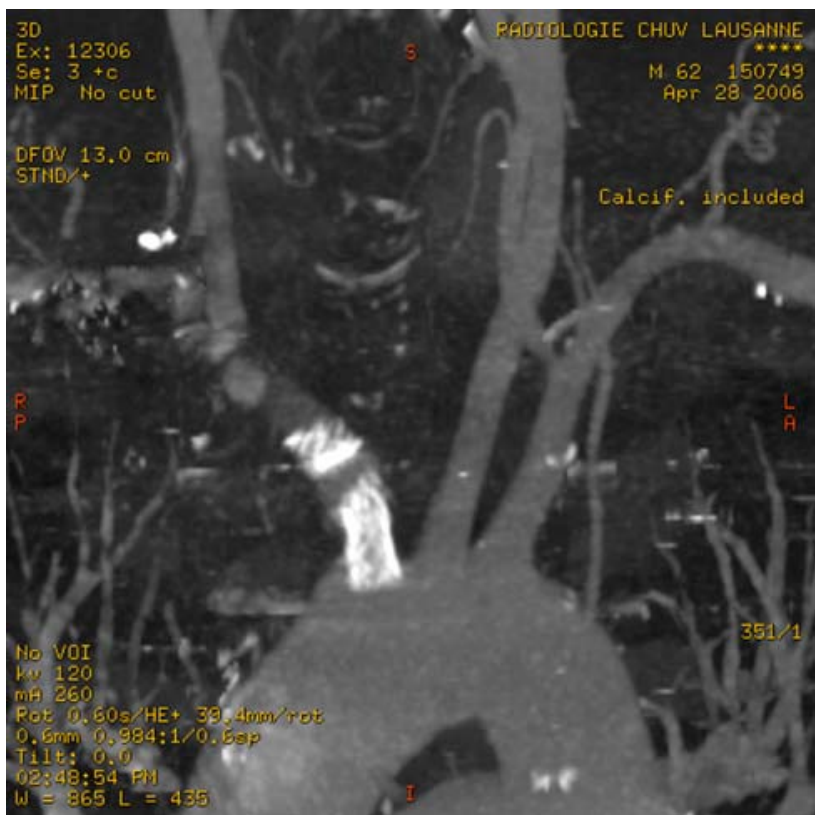

Fig. 3 CT scan. The ruptured upper extremity of the stent has moved and rotated. Blood is flowing through the meshes of the stent

angiography was performed to better evaluate the patency of the stent and revealed that the brachiocepalic trunk remained patent, with a $<40 \%$ in-stent re-stenosis. It also confirmed that the stent was ruptured (Fig. 4). The cranial fragment was shifted and rotated at a $90^{\circ}$ angle. Blood was flowing through the struts of the stent. There was no stenosis on the prevertebral subclavian artery. We estimated

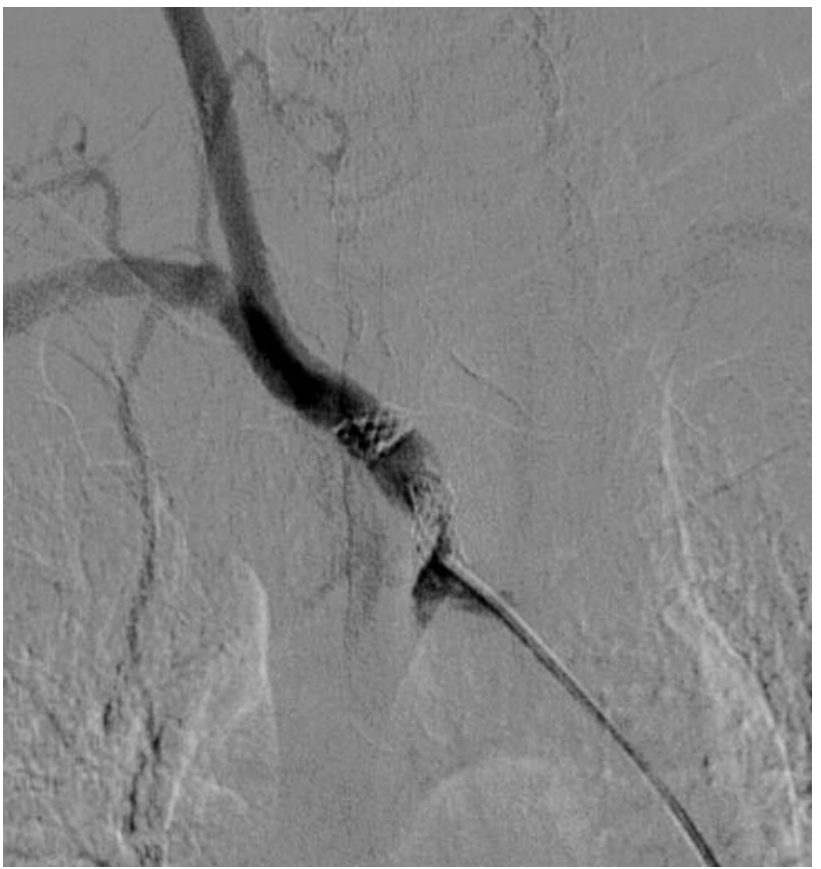

Fig. 4 Selective angiography confirming the rupture and rotation of the caudal stent extremity 


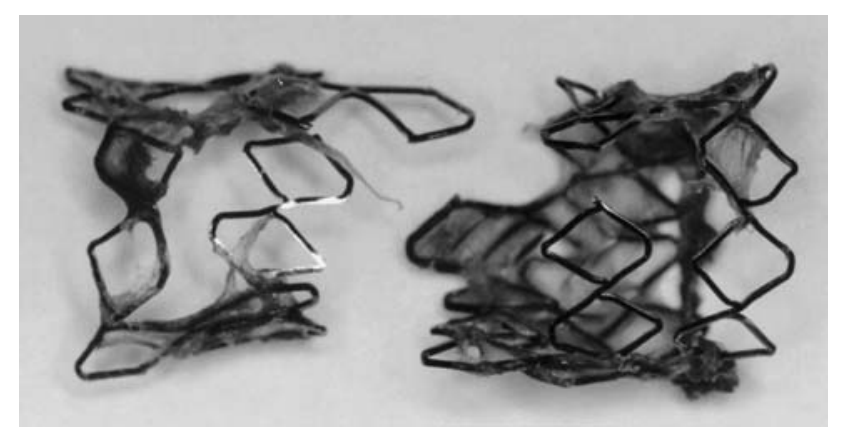

Fig. 5 Surgically resected fragments of the ruptured stent

that the flow through the struts of the stent had a hemodynamic effect similar to that of a significant stenosis, especially when associated with an in-flow impairment due to the moderate in-stent restenosis. We also estimated that the shifted and rotated position of the fragment made it prone to migrate farther or to be a potential source of distal emboli in the brain or arm. Since there was no possibility of endovascular management, the patient was referred to a cardiovascular surgeon, who successfully performed an aortobrachiocephalic trunk bypass and resected the stent (Fig. 5), by a localized thoracotomy. Postoperative assessment showed symmetry of brachial blood pressure and restored triphasic flow in the right subclavian and common carotid arteries.

\section{Discussion}

Isolated cases of stent fracture have been observed in the coronary artery [8], subclavian artery [9], iliac artery [10], femoropopliteal artery [11], and pulmonary artery [12]. Mechanical stress seems to be a risk factor for fracture [7]. Stents positioned in arteries frequently bent (i.e., femoropopliteal artery) or placed near a pulsatile structure (like the heart or great vessels) also have a higher risk of fracture [13]. Localized stiffness of the arterial wall may play a role in the breakage of the device, as observed with overlapping stents or stents used for intrastent restenosis [8]. The structure of the device certainly has an influence on its mechanical properties and solidity $[14,15]$. A recent prospective evaluation of stent fracture found $24.5 \%$ fractured stents at 10 months after femoropopliteal stenting [15]. These fractures were classified as single strut fracture in $48.4 \%$, moderate fracture in $26.6 \%$, and complete separation of fragments in $25.0 \%$. In that study, fracture rate was correlated with the length of the segment that had been covered by stents. Moreover, stent fracture was a predictor of intrastent restenosis and artery occlusion [15].

In this case we postulated that stent rupture may have had three origins. First, the brachiocephalic trunck is a pulsatile large vessel exerting continuous mechanical stress on the device. Second, the ruptured fragment (distal fragment) was located in the area of wall apposition defect of the stent, while the proximal fragment remained in the site of the minimum lumen diameter. One could imagine that the distal part, in contrast to the proximal one, would have been submitted to continuous systolodiastolic motion that induced microtraumatism at the junction between the two fragments and, subsequently, complete fracture of the stent struts. Migration of the stent after the fracture supported the absence of re-endothelialization of the stent, probably because of the wall apposition defect and the distal fragment motion. Third, the stent used may have mechanical properties that could explain this event. The Peiron stent is a premounted thermocrimped $316 \mathrm{~L}$ stainless-steel stent with a passive coating of amorphous silicon carbide. The stent contains 10 diamond-shaped cells per link, with two connecting struts between each link. This stent is no longer commercially available, having been upgraded to a new generation. To our knowledge, no similar complication with the Peiron stent has been reported in the literature.I

\section{Conclusion}

Stent fracture is a common complication of endovascular procedures. We have reported a particular case of stent rupture and migration in the brachiocephalic trunk where the flow through the stent's struts caused a unique hemodynamic pattern of vertebral steal syndrome. The apposition defect to the arterial wall seems to have been the major cause predisposing to rupture in this case.

\section{References}

1. ACC/AHA (2006) ACC/AHA 2005 practice guidelines for the management of patients with peripheral arterial disease (lower extremity, renal, mesenteric, and abdominal aortic). Circulation 113:463-654

2. Dormandy JA, Rutherford RB (2000) Management of peripheral arterial disease (PAD). TASC Working Group. J Vasc Surg 31:S1-S296

3. Schillinger M, Sabeti S, Loewe C, Dick P, Amighi J, Mlekusch W, Schlager O, Cejna M, Lammer J, Minar E (2006) Balloon angioplasty versus implantation of nitinol stents in the superficial femoral artery. N Engl J Med 354:1879-1888

4. Sullivan TM, Gray BH, Bacharach JM, Perl J 2nd, Childs MB, Modzelewski L, Beven EG (1998) Angioplasty and primary stenting of the subclavian, innominate and common carotid arteries in 83 patients. J Vasc Surg 28:1059-1065

5. Zaytzev AY, Stoyda AY, Smirnov VE, Scherbyuk AN, Kondrashin SA, Artukchina EG, Kikevitch VA (2006) Endovascular treatment of supra-aortic extracranial stenosis in patients with vertebrobasilar insufficiency symptoms. CardioVasc Interv Radiol 29:731-738

6. Amor M, Eid-Lidt G, Chati Z, Wilentz JR (2004) Endovascular treatment of the subclavian artery: stent implantation with or without predilatation. Cathet Cardiovasc Interv 63:364-370 
7. Laird JR (2006) Limitations of percutaneous transluminal angioplasty and stenting for the treatment of disease of the superficial femoral and popliteal arteries. J Endovasc Ther 13 (Suppl II):II30-II-40

8. Sianos G, Hofma S, Ligthart JM, Saia F, Hoye A, Lemos PA, Serruys PW (2004) Stent fracture and restenosis in the drugeluting stent era. Cathet Cardiovasc Interv 61:111-116

9. Phipp LH, Scott DJ, Kessel D, Robertson I (1999) Subclavian stents and stent-grafts: A cause for concern? J Endovasc Surg 6:223-226

10. Sachs BA, Miller A, Gottlieb M (1996) Fracture of an iliac artery Palmaz stent. J Vasc Interv Radiol 7:53-55

11. Duda SH, Pusich B, Richter G, Landwehr P, Oliva VL, Tielbeek A, Wiesinger B, Hak JB, Tielemans H, Ziemer G, Cristea E, Lansky A, Bérégi JP (2002) Sirolimus eluting stent for the treatment of obstructive superficial artery disease: six months results. Circulation 106:1505-1509
12. Knirsh W, Haas NA, Lewin MA, Uhlemann F (2003) Longitudinal stent fracture 11 months after implantation in the left pulmonary artery and successfull management by stent-in-stent maneuver. Cathet Cardiovasc Interv 58:116-118

13. Nakanishi T, Kondoh C, Nishikawa T, Satomi G, Nakazawa M, Imai Y, Momma K (1994) Intravascular stents for the management of pulmonary artery and right ventricular outflow obstruction. Heart Vessels 9:40-48

14. Duda SH, Bosiers M, Lammer J, Scheinert D, Zeller T, Tielbeek A, Anderson J, Wiesinger B, Tepe G, Lansky A, Mudde C, Tielemans H, Beregi JP (2005) Sirolimus-eluting versus bare nitinol stent for obstructiove superficial femoral artery disease: the SIROCCO II trial. J Vasc Interv Radiol 16:331-338

15. Scheinert D, Scheinert S, Sax J, Piorkowski C, Bräunlich S, Ulrich M, Biamino G, Schmidt A (2005) Prevalence and clinical impact of stent fractures after femoro-popliteal stenting. J Am Coll Cardiol 45:312-315 